${ }^{3}$ Department of Endocrinology, St. John's Medical College \& Hospital, Bangalore, India

${ }^{4}$ Department of Endocrinology, Nightingale Hospital, Kolkata, India

\title{
The impact of cardiovascular outcome trials on the choice of insulins in the management of type 2 diabetes mellitus: An expert review
}

\section{ABSTRACT}

Introduction. This expert review aims to address the epidemiology and pathophysiology of cardiovascular disease (CVD) in persons with type 2 diabetes mellitus (T2DM), help understand the various statistical considerations and interpretational nuances of cardiovascular outcome trials (CVOTs) in general, and discuss in particular, the CVOTs with insulins, and their impact on the choice of insulins in day-to-day clinical practice. Material and methods. The expert panel critically analysed published data from observational studies, randomized clinical trials, meta-analyses and CVOTs regarding cardiovascular (CV) safety of insulin preparations, and agreed on a series of consensus statements supported by available scientific evidence and the collective clinical judgement of the experts.

Results. A proportion of persons with T2DM have a high risk of CVD and CV mortality, which is partly contributed by insulin resistance-related, and hyperglycaemiarelated, risk factors. Over the past decade, CVOTs have become an integral part of the drug approval process of anti-diabetic therapies by the United States Food and Drug Administration (FDA). Most insulin preparations in use today, barring a few modern insulins, were introduced much before this regulatory requirement

Address for correspondence:

Dr Samit Ghosal

Nightingale Hospital, 11 Shakespeare Sarani, Kolkata, India Phone: +919674328281

e-mail: drsghosal2010@gmail.com

Clinical Diabetology 2018, 7, 5, 234-246

DOI: $10.5603 /$ DK.2018.0024

Received: 25.09.2018

Accepted: 28.09.2018 was put in place, and hence, have not undergone rigorous CVOTs. There is a large body of observational data concerning the CV safety of insulin preparations, which are often confusing and, at times, contradictory. In this background, it is reassuring to note that CVOTs of two basal insulin analogues, namely insulin glargine, studied in the Basal Insulin and Cardiovascular and Other Outcomes in Dysglycaemia Trial (ORIGIN), and insulin degludec, studied in the Efficacy and Safety of Degludec versus Glargine in Type 2 Diabetes Trial (DEVOTE), established their long-term CV safety. The DEVOTE trial provided additional safety data reporting fewer severe hypoglycaemic events with insulin degludec in comparison to insulin glargine.

Conclusions. This review critically analyses the two CVOTs of basal insulin analogues, in tandem with a general review of the methodological and interpretational aspects of CVOTs in general. The long-term CV safety of analogue basal insulins is discussed. The lack of CVOTs with prandial and pre-mixed insulins, either human or analogue, was identified as the main research gap in this area. (Clin Diabetol 2018; 7, 5: 234-246)

Key words: type 2 diabetes, insulin treatment, basal insulin, analogue insulin, cardiovascular safety, cardiovascular outcome trials, ORIGIN, DEVOTE

\section{Introduction}

Diabetes mellitus is a growing public health problem worldwide. According to the eighth edition of the International Diabetes Federation (IDF) Diabetes Atlas 2017, the number of people living with diabetes 


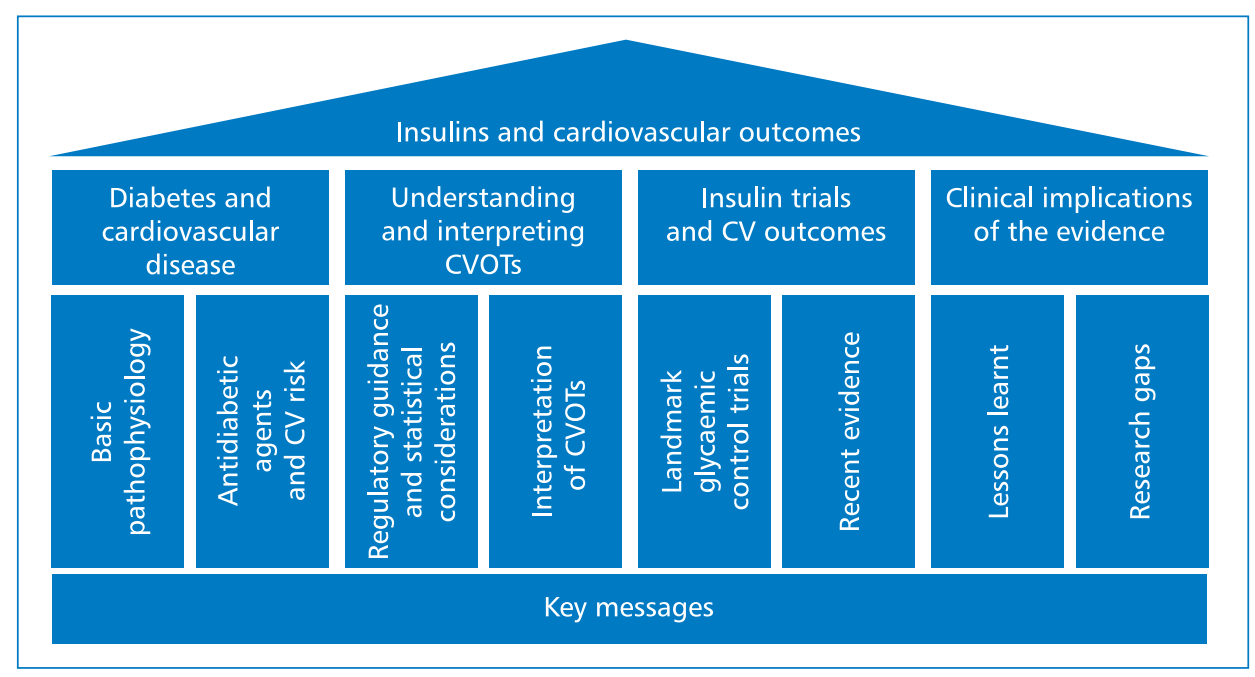

Figure 1. Framework for expert panel approach

globally was 425 million in 2017, and is estimated to reach 629 million by 2045 [1, 2]. India has the second highest number of people with the disease in the world.

People with type 2 diabetes mellitus (T2DM) have at least a two-fold higher risk of cardiovascular (CV) mortality than those without T2DM [4-6]. The risk of having a myocardial infarction (MI) in a person with T2DM of $>8$ years duration who has had no previous $\mathrm{MI}$ is as high as the risk in a non-diabetic person who has had a previous MI [7-9]. The CVD burden is higher among Asian Indian individuals, who not only have a higher predisposition to T2DM that develops at a younger age but also have a higher risk of coronary heart disease (CHD) as compared to their western counterparts [10].

Typical manifestations of cardiovascular disease (CVD) in a person with T2DM include CHD, ischaemic stroke, peripheral artery disease, and heart failure [3].

Exogenous insulin is an established blood-glucose-lowering agent, which has seen a steady growth in its use in people with T2DM over the recent years.; this rise in use is partly due to various guidelines recommending early use of insulin, and partly because of the availability of modern analogue insulins offering ease of administration, less weight gain, and lesser risk of hypoglycaemia [11-13]. However, in view of the growing concern on the CV safety profile of oncecommon therapies [14-16], there is a need for a more close evaluation of the CV safety profile of exogenous insulin in T2DM $[12,17]$.

The guidance issued by FDA in 2008 recommended that any new anti-diabetic agent should not increase CV risk to an unacceptable extent [18]. Since then, cardiovascular outcome trials (CVOTs) have become an integral part of drug approval process of anti-diabetic therapies.
However, despite their simplicity in design, many primary care physicians, and the occasional expert, misinterpret glycaemic efficacy trials as CVOTs $[17,19]$.

Therefore, this expert panel set out to address the epidemiology and pathophysiology of CVD in T2DM, assess the statistical considerations and interpretation of CVOTs in terms of regulatory guidance, review the available CVOTs with insulin, and their impact on the choice of insulin in people with T2DM in clinical practice.

\section{Methods}

A panel of endocrinologists and physicians specialising in the management of diabetes met to develop a consensus statement regarding the CV safety of the various insulin preparations and its impact on the choice of insulin in people with T2DM in the Indian setting. The panel critically analysed published data from observational studies, randomized clinical trials, meta-analyses, and CVOTs with insulin, and agreed on a series of consensus statements supported by scientific evidence and experts' clinical judgement. The expert panel approached the task by reviewing and addressing four areas; a) diabetes and CVD (basic pathophysiology and CVD risk of antidiabetic agents), b) understanding and interpreting CVOTs (regulatory guidance and statistical considerations), c) insulin trials and CV outcomes (landmark glycaemic control trials, dedicated CVOTs), d) clinical implications of the evidence (Fig. 1).

\section{Diabetes as potential CHD risk equivalent}

People with T2DM have a 2-4 fold higher risk of coronary artery disease (CAD) and ischaemic stroke, 2-8 fold higher risk of heart failure, and at least 
a two-fold higher risk of CV mortality than those without diabetes [4-6].

The CArdiovascular disease research using LInked Bespoke studies and Electronic health Records (CALIBER) program, a population-based study of nearly 2 million individuals, of whom $1.2 \%$ had T2DM, with a median follow-up of 5.5 years, revealed a strong association between T2DM and 12 specific CVD disease outcomes [21].

The East-West study from Finland with 1,373 nondiabetic and 1,059 people with T2DM revealed that a person with T2DM without a previous MI has as high a risk of suffering from a MI as a non-diabetic individual with a previous MI over 7 [7] and 18-year [8] follow-up. This led to the designation of T2DM as a " $\mathrm{CHD}$ risk equivalent", and this was also recommended by the National Cholesterol Education Program (NECP) Adult Treatment Panel (ATP) III guidelines in 2001 [22]. However, the 2013 American College of Cardiology (ACC)/ /American Heart Association (AHA) risk assessment guidelines recommended consideration of diabetes as a predictor of, rather than an automatic CHD risk equivalent, and suggested the use of global risk assessment to help discriminate those with a higher CVD risk from those with a lower risk [23].

\section{Pathophysiology of CVD in diabetes: The role of hyperglycaemia and insulin resistance}

Hyperglycaemia, insulin resistance and/or hyperinsulinemia, dyslipidaemia, inflammation, reactive oxygen species, endothelial dysfunction, hypercoagulability, and vascular calcification are among the many factors that contribute to atherosclerotic CVD in diabetes [3]. In addition, people with T2DM have greater atherosclerotic plaque burden, higher atheroma volume, and smaller coronary artery lumen diameter than persons without diabetes [3, 24].

Insulin resistance is evident prior to the onset of pre-diabetes or diabetes whereas dysglycaemia develops only when pre-diabetes sets in and worsens with development of diabetes [3]. There is a direct association between hyperglycaemia and microvascular disease, whereas CV risk is related to insulin resistance, much before the development of T2DM $[4,25]$.

\section{Paradoxical increase in cardiovascular risk with certain anti-hyperglycaemic agents}

CV risk associated with sulfonylureas became a concern when an interim analysis of University Group Diabetes Program (UGDP) in 1969 showed a statistically significant increase in CV deaths associated with tolbutamide [33].
CV hazard for the first dual-PPAR (peroxisome proliferator-activated receptor) agonist, muraglitazar was seen during extension trials indicating an excess incidence of the composite end point of death, major adverse CV events (MACE) and CHF (congestive heart failure) in muraglitazar treated persons when compared to placebo or pioglitazone [36]. Hence, further development of the drug was halted [37].

CV safety of rosiglitazone was evaluated in a metaanalysis of 42 trials that demonstrated a significant increase in the risk of $\mathrm{Ml}$, and a non-significant increase in CV mortality [39]. A follow-up meta-analysis of four randomized controlled trials (RCTs) involving 14,291 patients examined the long-term effects of rosiglitazone on MI, HF, and CV mortality [40]. The results confirmed the association of rosiglitazone with a significantly elevated risk of $\mathrm{MI}$ and heart failure, but not with an increase in CV mortality [40]. This association of rosiglitazone with increased CV risk $[39,40]$ emphasized the need for a closer evaluation of anti-diabetic therapies from CV safety perspective (Table 1).

In 2008, FDA issued guidance to pharmaceutical industry on the conduct of clinical studies to prove that anti-diabetic drugs confer to acceptable levels of CV safety [18].The "FDA guidance" recommended that anti-diabetic drugs should not increase CV risk to an unacceptable extent [18]. CVOTs since then have become an integral part of the drug approval process.

\section{Simplifying the understanding of CVOTs}

Despite evaluating the same drug of interest, diabetes efficacy trials and CVOTs exhibit differences in both the design and the measured outcomes. The primary purpose of conducting a diabetes efficacy trial is to evaluate the glucose-lowering capability of the study drug when compared to either placebo or an active comparator, and CV adverse events are documented during the course of the trial. In traditional efficacy trials, CV events of interest are neither pre-specified nor independently adjudicated [26].

On the other hand, CVOTs serve to compare the rates of CV events of a study drug with that of a control, usually a placebo, in order to assess the study drug's impact on a patient's CV risk; both active treatment and placebo arms are assessed for their impact on MACE (Major Adverse Cardiovascular Events). The interpretation of CVOT starts with understanding the aim of the study (whether powered for non-inferiority or superiority), the study design, the background prevalence of the event(s) in question, the pre-specified primary and secondary end-points, the need for pre-adjudication of these end points, and the ability to replicate the data [27]. 


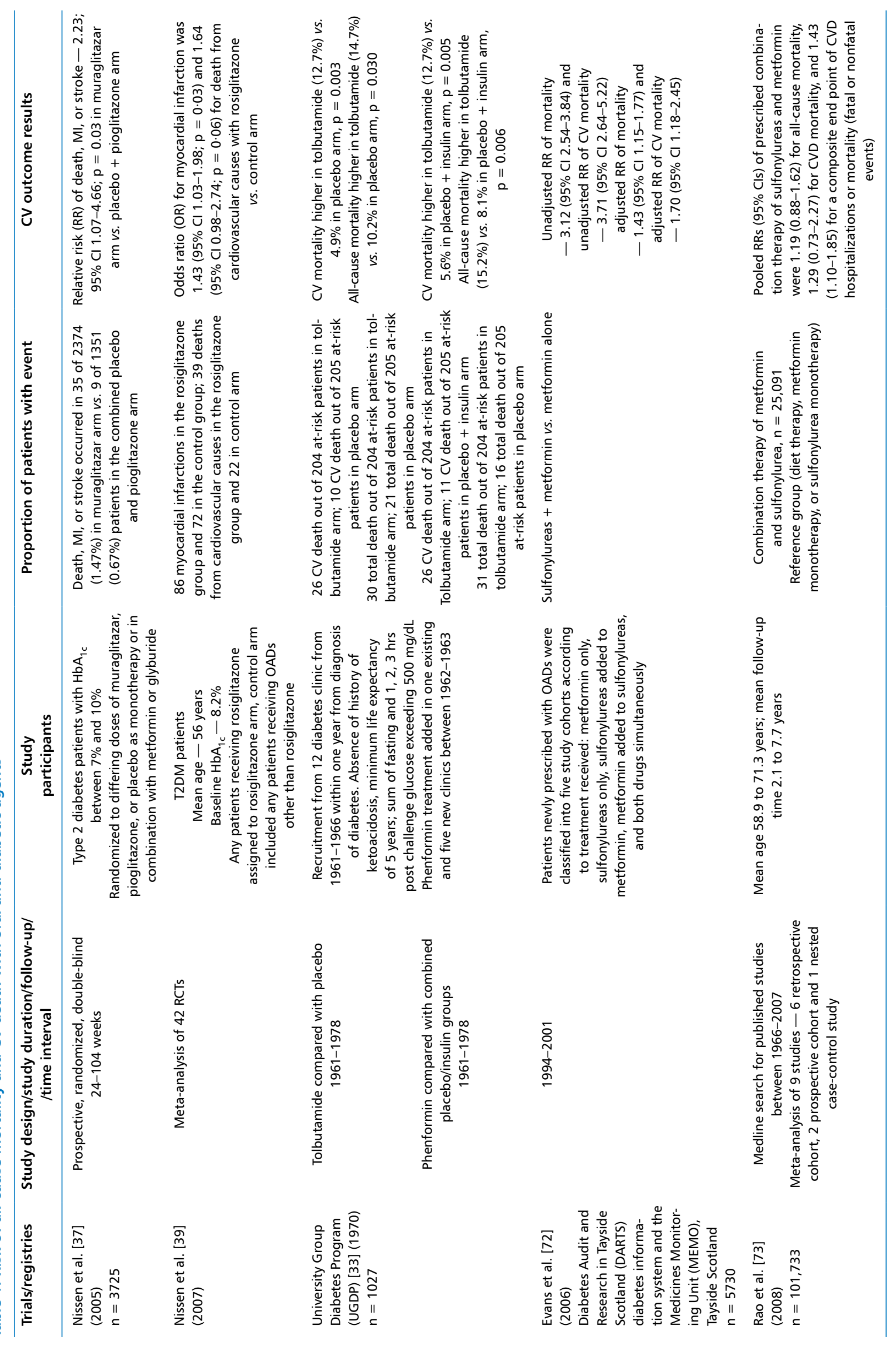




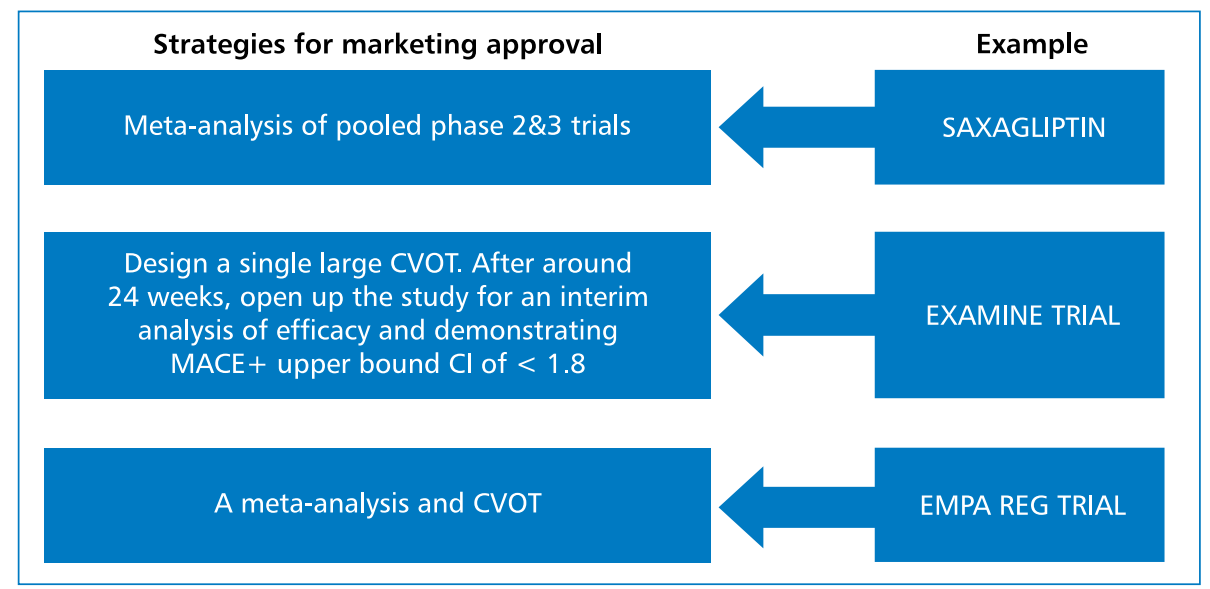

Figure 2. Different strategies for approval of anti-hyperglycaemic agents. Adapted from [27]

A pre-defined number of MACEs have to occur during the clinical program to provide adequate statistical power for the outcome of interest. Assuming that a study drug is neutral with respect to its CV safety, there must be approximately 122 MACE events to provide sufficient statistical power to rule out CV harm with an upper confidence limit of 1.8. Approximately 611 MACE events need to accrue to provide sufficient statistical power to rule out harm with an upper confidence limit of 1.3.

As per FDA guidance, CVOTs should include a sufficient number of persons with T2DM who are at higher risk for CV events. This shall allow for an adequate number of events to provide a sound estimate of risk. High-risk category includes those with advanced age, longer duration of diabetes, history of CV disease, presence of proteinuria, and/or chronic kidney disease $[28,29]$.

One potential disadvantage of the regulatory requirement for any new anti-diabetic drug to demonstrate at least no CV harm in a dedicated CVOT is the potential delay in the introduction of the newer antidiabetic medications for glycaemic control. The new anti-diabetic medication can be made available earlier by following any one of the three strategies (Fig. 2) [27].

\section{Evidence from observational studies}

Initial concerns regarding CV safety of insulin in T2DM emerged from epidemiological data. A population-based study in Canada found a dose-response relationship between insulin use and all-cause mortality [45]. In another epidemiological study in UK, insulin treatment was reported to be associated with increased mortality compared to a combination of metformin and sulfonylurea [46]. A number of other observational studies have also reported an increased risk of cardiac events [47, 48] and CVD [49] in insulin-treated persons with T2DM.

Epidemiological data from the 2000-2010 UK General Practice Research Database revealed that insulin monotherapy resulted in a poorer outcome when compared to either metformin or sulfonylurea monotherapy for the primary end point of CV events and stroke, and all-cause mortality [12]. However, there were significant differences between the cohorts in terms of baseline characteristics, such as higher rate of prior vascular morbidity, and higher $\mathrm{HbA}_{1 \mathrm{c}}$ in the insulin-treated group, which could be responsible for the observed poor outcomes [12]. US NHANES I study revealed that the use of insulin was associated with a non-significant increase in all-cause mortality, but here was no significant increase in CVD [50].

However, these observational studies were not specifically designed to address the CV safety of insulin. In the absence of randomisation, a number of confounding variables including differences in age, duration of diabetes, presence of comorbidities, prevailing CV risk and severity of insulin resistance make it difficult to compare the treatment groups [12, 45, 51-55]. A dedicated CVOT with insulin, with pre-specified and adjudicated end points, is necessary to address the CV safety of insulin (Table 2).

\section{Insulins and cardiovascular outcome trials}

ORIGIN (Outcome Reduction with Initial Glargine Intervention) trial [68] assessed the effect of basal insulin glargine, compared to standard of care, on three point MACE (CV death, non-fatal MI, non-fatal stroke) in persons with newly diagnosed T2DM or with pre-diabetes. There were two co-primary composite cardiovascular outcomes. The first was death from 


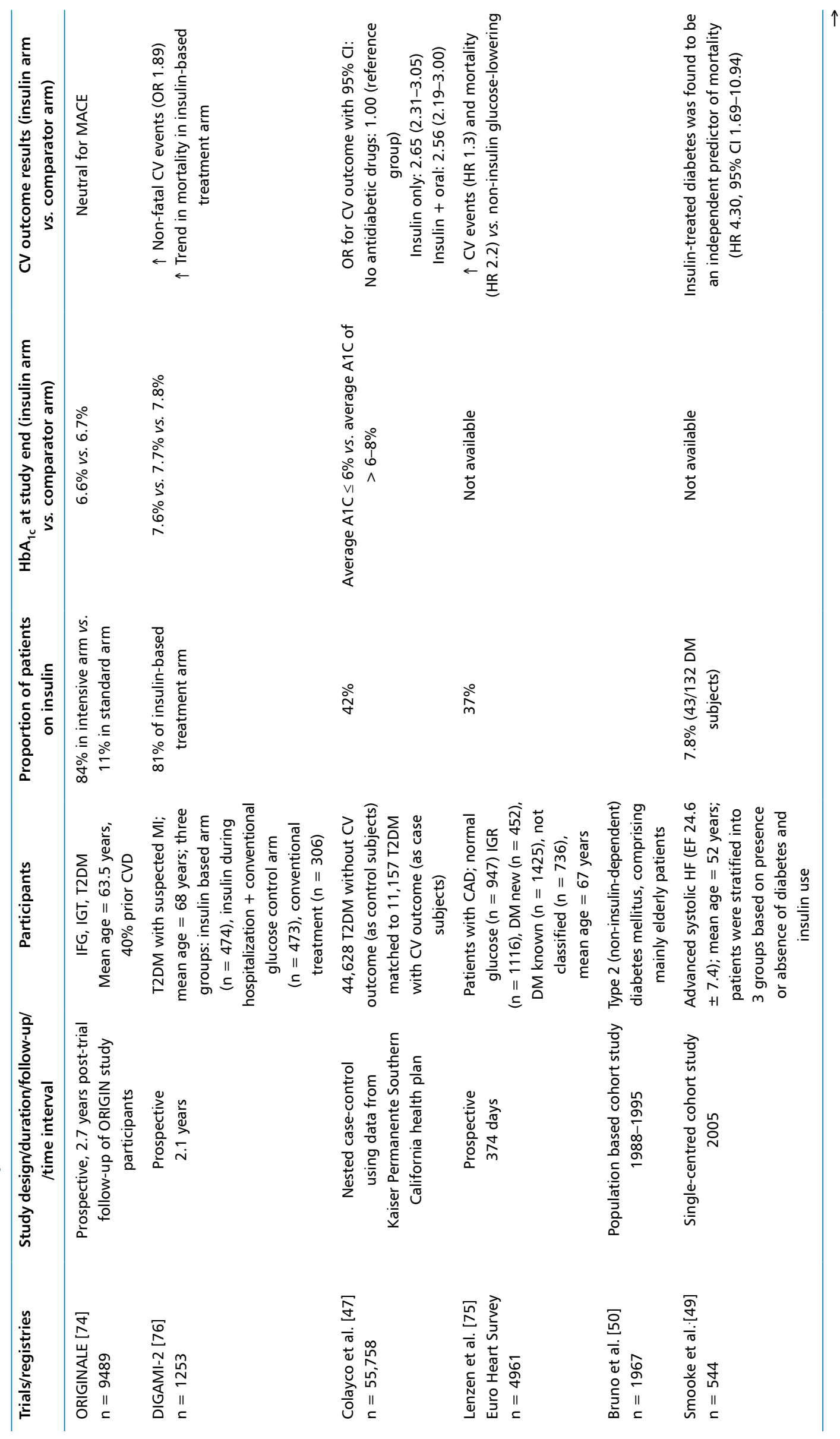




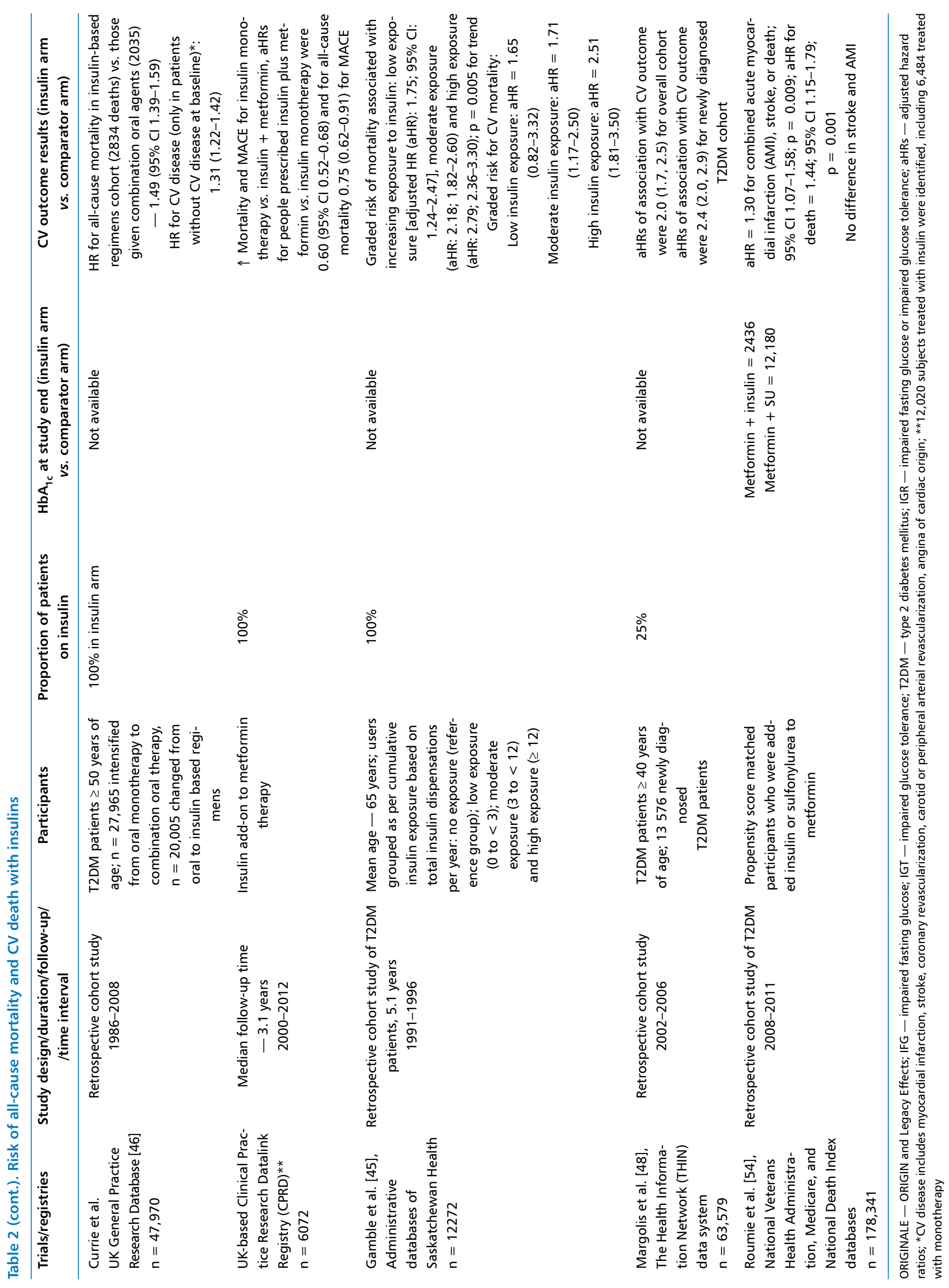


Table 3. Parameters of the ORIGIN and DEVOTE trials [68, 69]

\begin{tabular}{|c|c|c|}
\hline Parameter & ORIGIN & DEVOTE \\
\hline \multirow[t]{2}{*}{ Primary objective } & To assess the effects of glargine & To confirm the CV safety of degludec \\
\hline & on CV outcomes & as per regulatory requirement \\
\hline Study population & T2D/IFG/IGT + high CVD risk & $T 2 D+$ high CVD risk \\
\hline Design & Open-label & Double-blind \\
\hline \multirow[t]{2}{*}{ Comparator arm } & SOC as per investigator's discretion & Insulin glargine U100 \\
\hline & (11.4\% of patients used insulin at EOT) & \\
\hline Target FPG & $<95 \mathrm{mg} / \mathrm{dl}$ & $71-90 \mathrm{mg} / \mathrm{dl}$ \\
\hline Baseline $\mathrm{HbA}_{1 \mathrm{c}}$ & $6.4 \%$ & $8.4 \%$ \\
\hline Prior CV disease & $58.8 \%$ & $85.2 \%$ \\
\hline HR for primary endpoint & $1.02(0.94-1.11)$ & $0.91(0.78-1.06)$ \\
\hline (3P MACE) & $p=0.63$ & $p<0.001$ for non-inferiority \\
\hline
\end{tabular}

cardiovascular causes, nonfatal myocardial infarction, or nonfatal stroke, and the second was a composite of any of these events, a revascularization procedure (cardiac, carotid, or peripheral), or hospitalization for heart failure. Insulin glargine had a neutral effect on $\mathrm{CV}$ outcomes. Rates of the first co-primary CV outcome of MI, stroke, or CV death, and the second co-primary outcome of $\mathrm{MI}$, stroke, CV death, revascularization and heart failure were similar in the insulin glargine and the standard care groups (2.94 vs. 2.85 per 100 person-years; and 5.52 vs. 5.28 per 100 person-years, respectively). Results showed that the progression from pre-diabetes to diabetes was delayed by $28 \%$ in the insulin glargine arm at one month following completion of the trial, and the number of persons in remission was $20 \%$ when reassessed after 100 days (Fig. 3, Table 3) [68].

DEVOTE is the first ever regulatory CVOT comparing two basal insulins, once daily insulin degludec vs. insulin glargine, in 7637 persons with T2DM.The primary composite outcome occurred in 325 patients (8.5\%) in the degludec group and in 356 patients (9.3\%) in the glargine group [hazard ratio $0.91 ; 95 \%$ confidence interval $(\mathrm{Cl}) 0.78-1.06 ; \mathrm{p}<0.001$ for noninferiority in a one-sided test]. There was no significant difference in the incidence of death in the degludec and glargine groups [202 patients (5.3\%) vs. 221 patients (5.8\%); hazard ratio $0.91 ; 95 \% \mathrm{Cl} 0.76-1.11 ; \mathrm{p}=0.35]$. There was no statistically significant difference between insulin glargine and insulin degludec with respect to three point MACE (CV death, non-fatal MI, non-fatal stroke) [69].

\section{Lessons learnt}

Data from DEVOTE and ORIGIN established the CV safety of the basal insulin analogues glargine and degludec. ORIGIN revealed that glargine had a neutral effect on CV outcome despite an increased incidence of hypoglycaemia and modest increase in body weight [68]. DEVOTE is the first dedicated regulatory CVOT trial with an insulin, where insulin degludec was compared to insulin glargine. Insulin degludec was non-inferior to insulin glargine in demonstrating CV safety. There was less hypoglycemia in the degludec arm when compared to glargine [69].

\section{Research gap}

There is very limited information concerning the cardiovascular safety of various insulin preparations. Observational data, with all its limitations and biases, have tended to attribute an increased CV risk to insulin. However, in contrast, data from the two large CVOTs with basal insulin analogues is very reassuring. However, to date, there is no CVOT data concerning the CV safety of short/rapid acting human or analogues insulins, premixed human or analogue insulins, co-formualtion insulin, or the intermediate acting insulin $\mathrm{NPH}$.

\section{Conclusion}

Insulin therapy has remained an important therapeutic agent in the treatment of diabetes mellitus, and it is thus crucial to assess its CV safety as mandated by FDA. CV safety of insulins was earlier assessed through data from observational studies, which yielded conflicting results, till the availability of CV outcome data 


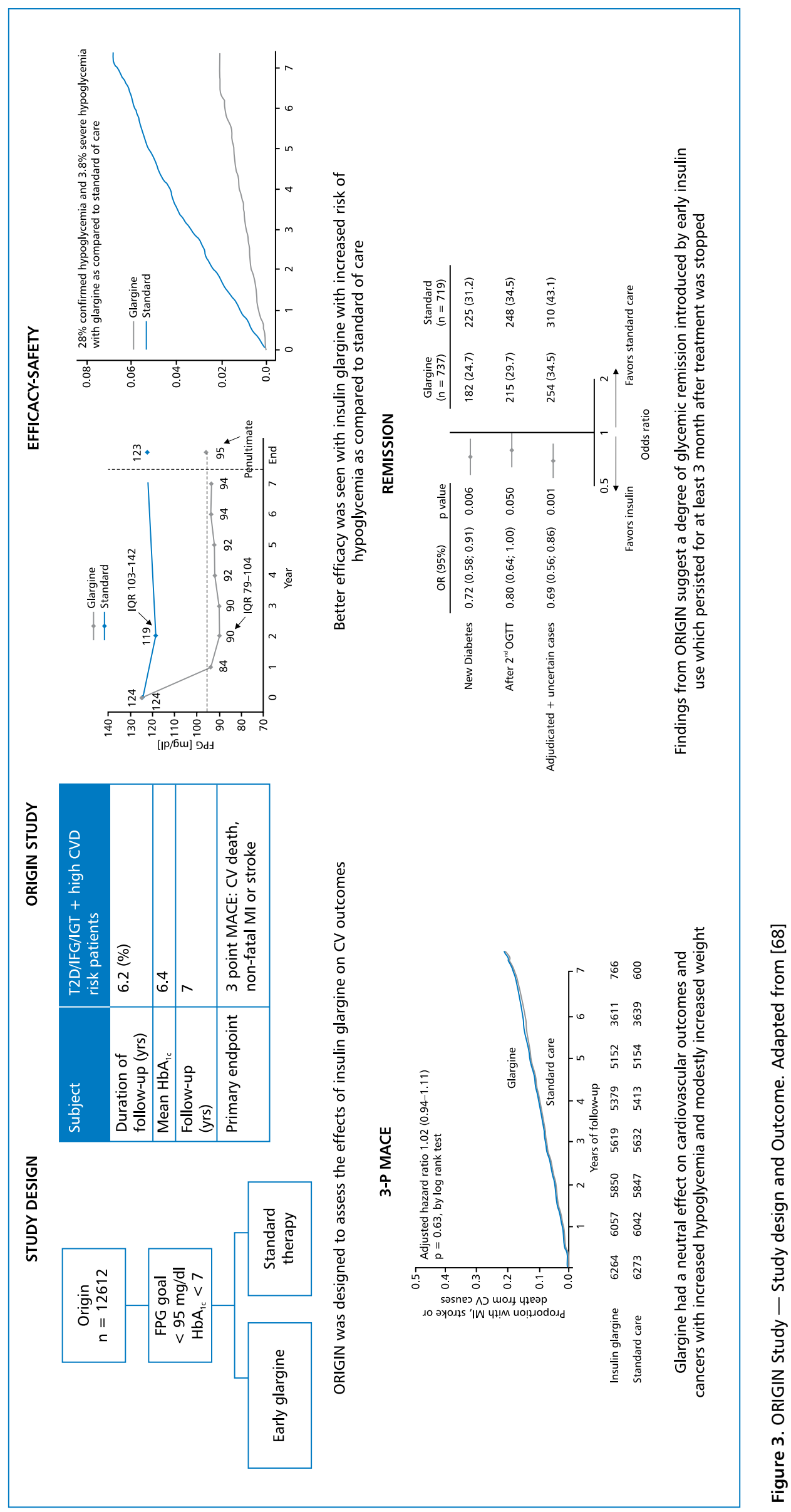




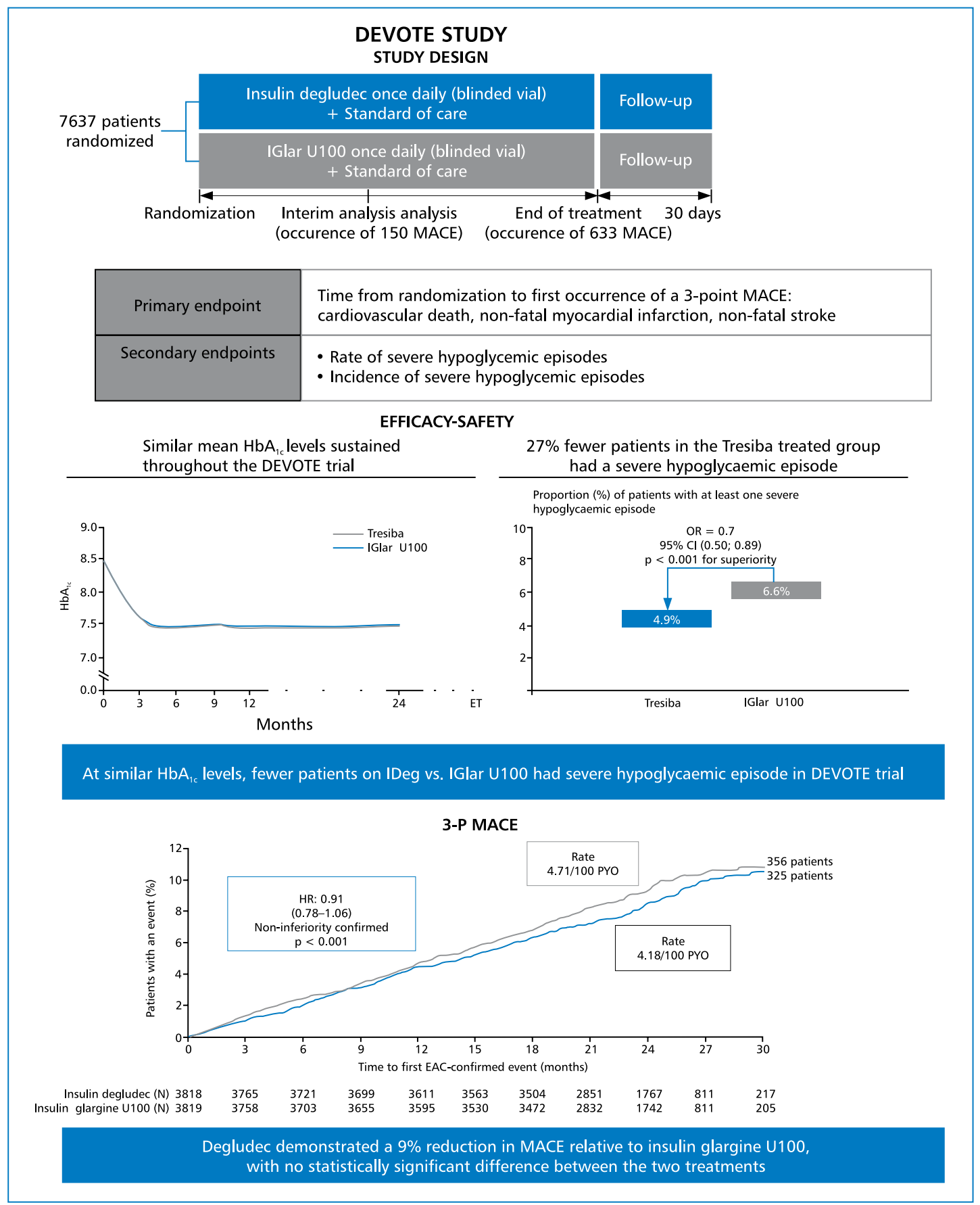

Figure 4. DEVOTE Study design and Outcome. Adapted from [77]

from randomised controlled trails with basal insulin analogues. The ORIGIN and DEVOTE trials have demonstrated the cardiovascular safety of insulin degludec and insulin glargine. There was lesser hypoglycaemia, and lesser day-to-day fasting glycaemic variability with insulin degludec when compared to insulin glargine, but this did not translate into CV benefits. More evidence is required concerning the CV safety of other insulin preparations, including human and analogue prandial and pre-mixed insulins to allow appropriate insulin choices.

\section{Author statement}

The authors declare that: The manuscript has been read and approved by all the authors, the requirements for authorship have been met, and each author believes that the manuscript represents honest work. 


\section{Conflict of interest None declared.}

\section{REFERENCES}

1. International Diabetes Federation (IDF). International Diabetes Federation (IDF). In: Dilworth J, Stuart-Jones M. ed. International Year Book and Statesmen's Who's Who. IDF Diabetes Atlas Update, Brussels 2018: 8.

2. Shaw JE, Sicree RA, Zimmet PZ. Global estimates of the prevalence of diabetes for 2010 and 2030. Diabetes Res Clin Pract. 2010; 87(1): 4-14, doi: 10.1016/j.diabres.2009.10.007, indexed in Pubmed: 19896746

3. Low Wang CC, Hess CN, Hiatt WR, et al. Clinical Update: Cardiovascular Disease in Diabetes Mellitus: Atherosclerotic Cardiovascular Disease and Heart Failure in Type 2 Diabetes Mellitus - Mechanisms, Management, and Clinical Considerations. Circulation. 2016; 133(24): 2459-2502, doi: 10.1161/CIRCULATIONAHA.116.022194, indexed in Pubmed: 27297342

4. Martín-Timón I, Sevillano-Collantes C, Segura-Galindo A, et al. Type 2 diabetes and cardiovascular disease: Have all risk factors the same strength? World J Diabetes. 2014; 5(4): 444-470, doi: 10.4239/wjd.v5.i4.444, indexed in Pubmed: 25126392.

5. Rao Kondapally Seshasai S, Kaptoge S, Thompson A, et al. Emerging Risk Factors Collaboration. Diabetes mellitus, fasting glucose, and risk of cause-specific death. N Engl J Med. 2011; 364(9): 829-841, doi: 10.1056/NEJMoa1008862, indexed in Pubmed: 21366474.

6. Laakso M, Lehto S. Epidemiology of macrovascular disease in diabetes. Diabetes Rev. 1997; 5: 294-315.

7. Haffner SM, Lehto S, Rönnemaa T, et al. Mortality from coronary heart disease in subjects with type 2 diabetes and in nondiabetic subjects with and without prior myocardial infarction. N Engl J Med. 1998; 339(4): 229-234, doi: 10.1056/ /NEJM199807233390404, indexed in Pubmed: 9673301.

8. Juutilainen $A$, Lehto $S$, Rönnemaa $T$, et al. Type 2 diabetes as a "coronary heart disease equivalent": an 18-year prospective population-based study in Finnish subjects. Diabetes Care. 2005; 28(12): 2901-2907, doi: 10.2337/diacare.28.12.2901, indexed in Pubmed: 16306552 .

9. Wannamethee SG, Shaper AG, Whincup PH, et al. Impact of diabetes on cardiovascular disease risk and all-cause mortality in older men: influence of age at onset, diabetes duration, and established and novel risk factors. Arch Intern Med. 2011; 171(5): 404-410, doi: 10.1001/archinternmed.2011.2, indexed in Pubmed: 21403036.

10. Unnikrishnan R, Anjana RM, Mohan V. Diabetes mellitus and its complications in India. Nat Rev Endocrinol. 2016; 12(6): 357-370. Review.

11. Currie CJ, Peters JR, Evans M. Dispensing patterns and financial costs of glucose-lowering therapies in the UK from 2000 to 2008. Diabet Med. 2010; 27(7): 744-752, doi: 10.1111/j.14645491.2009.02849.x, indexed in Pubmed: 20636954.

12. Currie CJ, Poole CD, Evans $M$, et al. Mortality and other important diabetes-related outcomes with insulin vs other antihyperglycemic therapies in type 2 diabetes. J Clin Endocrinol Metab. 2013; 98(2): 668-677, doi: 10.1210/jc.2012-3042, indexed in Pubmed: 23372169.

13. American Diabetes Association Standards of medical care in diabetes. Diabetes Care. 2011; 34: S11-S61.

14. Yudkin JS, Richter B, Gale EAM. Intensified glucose lowering in type 2 diabetes: time for a reappraisal. Diabetologia. 2010; 53(10): 2079-2085, doi: 10.1007/s00125-010-1864-z, indexed in Pubmed: 20686748.

15. European Medicines Agency 2010 European Medicines Agency update on ongoing benefit-risk review of Avandia, Avandamet and Avaglim. http://www.ema.europa.eu/docs/en_GB/ /document_library/Press_release/2010/07/WC500094981. pdfAccessed August 5, 2012.
16. FDA 2010. Drug Safety Communication: Ongoing safety review of Actos (pioglitazone) and potential increased risk of bladder cancer after two years exposure. Available from URL http://www. fda.gov/Drugs/Drugsafety/ucm226214.htm.

17. John M, Gopalakrishnan Unnikrishnan A, Kalra S, et al. Cardiovascular outcome trials for anti-diabetes medication: A holy grail of drug development? Indian Heart J. 2016; 68(4): 564-571, doi: 10.1016/j.ihj.2016.02.017, indexed in Pubmed: 27543483.

18. Guidance for Industry. Diabetes Mellitus - Evaluating Cardiovascular Risk in New Antidiabetic Therapies to Treat Type 2 Diabetes. https://www.fda.gov/downloads/drugs/guidancecomplianceregulatory\%20information/guidances/ucm071627.pdf (2018-10-01).

19. Hiatt WR, Kaul S, Smith RJ. The cardiovascular safety of diabetes drugs - insights from the rosiglitazone experience. $N$ Engl J Med. 2013; 369(14): 1285-1287, doi: 10.1056/NEJMp1309610, indexed in Pubmed: 23992603.

20. Mohan V, Shanthirani CS, Deepa M, et al. Mortality rates due to diabetes in a selected urban south Indian population - the Chennai Urban Population Study [CUPS-16]. J Assoc Physicians India. 2006; 54: 113-117.

21. Shah AD, Langenberg C, Rapsomaniki E, et al. Type 2 diabetes and incidence of cardiovascular diseases: a cohort study in 1.9 million people. Lancet Diabetes Endocrinol. 2015; 3(2): 105-113, doi: 10.1016/S2213-8587(14)70219-0, indexed in Pubmed: 25466521.

22. Expert Panel on Detection, Evaluation, and Treatment of High Blood Cholesterol in Adults. Executive Summary of The Third Report of The National Cholesterol Education Program (NCEP) Expert Panel on Detection, Evaluation, And Treatment of High Blood Cholesterol In Adults (Adult Treatment Panel III). JAMA. 2001; 285(19): 2486-2497, indexed in Pubmed: 11368702.

23. Goff D, Lloyd-Jones D, Bennett G, et al. 2013 ACC/AHA Guideline on the Assessment of Cardiovascular Risk: A Report of the American College of Cardiology/American Heart AssociationTask Force on Practice Guidelines. Journal of the American College of Cardiology. 2014; 63(25): 2935-2959, doi: 10.1016/j.jacc.2013.11.005.

24. Nicholls SJ, Tuzcu EM, Kalidindi S, et al. Effect of diabetes on progression of coronary atherosclerosis and arterial remodeling: a pooled analysis of 5 intravascular ultrasound trials. J Am Coll Cardiol. 2008; 52(4): 255-262, doi: 10.1016/j.jacc.2008.03.051, indexed in Pubmed: 18634979.

25. Rydén L, Grant PJ, Anker SD, et al. The Task Force on diabetes, prédiabetes and cardiovascular diseases of the European Society of Cardiology (ESC) and developed in collaboration with the European Association for the Study of Diabetes (EASD). ESC Guidelines on diabetes, pre-diabetes and cardiovascular diseases, developed in collaboration with the EASD. Eur Heart J. 2013; 34: 3035-3087, doi: 10.1093/eurheartj/eht108.

26. John M, Gopalakrishnan Unnikrishnan A, Kalra S, et al. Cardiovascular outcome trials for anti-diabetes medication: $A$ holy grail of drug development? Indian Heart J. 2016; 68(4): 564-571, doi: 10.1016/j.ihj.2016.02.017, indexed in Pubmed: 27543483.

27. Ghosal S. Cardio Vascular Outcomes Trials (CVOTs) with AntiHyperglycemic Agents: Demystifying Statistical Complexities. Journal of Diabetes, Metabolic Disorders \& Control. 2017; 4(4): 00116, doi: 10.15406/jdmdc.2017.04.00116.

28. Geiger MJ, Mehta C, Turner JR, et al. Clinical Development Approaches and Statistical Methodologies to Prospectively Assess the Cardiovascular Risk of New Antidiabetic Therapies for Type 2 Diabetes. Ther Innov Regul Sci. 2015; 49(1): 50-64, doi: 10.1177/2168479014549860, indexed in Pubmed: 30222452

29. Accessed US Food and Drug Administration. Guidance for industry: diabetes mellitus - evaluating cardiovascular risk in new antidiabetic therapies to treat type 2 diabetes. http://www.fda.gov/ /downloads/drugs/guidancecomplianceregulatoryinformation/ guidances/ucm071627.pdf. Published December 2008. (2017-27-02).

30. Mazzone T, Chait A, Plutzky J. Cardiovascular disease risk in type 2 diabetes mellitus: insights from mechanistic studies. Lancet. 2008; 371(9626): 1800-1809, doi: 10.1016/S0140-6736(08)60768-0, indexed in Pubmed: 18502305. 
31. St Onge EL, Motycka CA, Miller SA. A review of cardiovascular risks associated with medications used to treat type-2 diabetes mellitus. P T. 2009; 34(7): 368-378, indexed in Pubmed: 20140101.

32. Panicker GK, Karnad DR, Salvi V, et al. Cardiovascular risk of oral antidiabetic drugs: current evidence and regulatory requirements for new drugs. J Assoc Physicians India. 2012; 60: 56-61, indexed in Pubmed: 22715547.

33. Meinert CL, Knatterud GL, Prout TE, et al. A study of the effects of hypoglycemic agents on vascular complications in patients with adult-onset diabetes. II. Mortality results. Diabetes. 1970; 19: 789-830, indexed in Pubmed: 4926376.

34. Patel A, MacMahon S, Chalmers J, et al. ADVANCE Collaborative Group. Intensive blood glucose control and vascular outcomes in patients with type 2 diabetes. N Engl J Med. 2008; 358(24): 2560-2572, doi: 10.1056/NEJMoa0802987, indexed in Pubmed: 18539916.

35. Gerstein HC, Miller ME, Byington RP, et al. Action to Control Cardiovascular Risk in Diabetes Study Group. Effects of intensive glucose lowering in type 2 diabetes. N Engl J Med. 2008; 358(24): 2545-2559, doi: 10.1056/NEJMoa0802743, indexed in Pubmed: 18539917

36. Muraglitazar briefing document. www.fda.gov/ohrms/dockets/ /ac/05/briefing/2005-4169B2_02_03-FDA- MedOff-Safety.pdf (2018-10-01).

37. Nissen SE, Wolski K, Topol EJ. Effect of muraglitazar on death and major adverse cardiovascular events in patients with type 2 diabetes mellitus. JAMA. 2005; 294(20): 2581-2586, doi: 10.1001/jama.294.20.joc50147, indexed in Pubmed: 16239637.

38. Dormandy JA, Charbonnel B, Eckland DJA, et al. PROactive Investigators. Secondary prevention of macrovascular events in patients with type 2 diabetes in the PROactive Study (PROspective pioglitAzone Clinical Trial In macroVascular Events): a randomised controlled trial. Lancet. 2005; 366(9493): 1279-1289, doi: 10.1016/S0140-6736(05)67528-9, indexed in Pubmed: 16214598.

39. Nissen SE, Wolski K. Effect of rosiglitazone on the risk of myocardial infarction and death from cardiovascular causes. N Engl J Med. 2007; 356(24): 2457-2471, doi: 10.1056/NEJMoa072761, indexed in Pubmed: 17517853.

40. Singh S, Loke YK, Furberg CD. Long-term risk of cardiovascular events with rosiglitazone: a meta-analysis. JAMA. 2007; 298(10): 1189-1195, doi: 10.1001/jama.298.10.1189, indexed in Pubmed: 17848653.

41. Home PD, Pocock SJ, Beck-Nielsen H, et al. RECORD Study Group. Rosiglitazone evaluated for cardiovascular outcomes - an interim analysis. N Engl J Med. 2007; 357(1): 28-38, doi: 10.1056/NEJMoa073394, indexed in Pubmed: 17551159.

42. Duckworth W, Abraira C, Moritz T. Glucose Control and Vascular Complications in Veterans with Type 2 Diabetes. Journal of Vascular Surgery. 2009; 360: 129-139, doi: 10.1016/j.jvs.2009.02.026.

43. Kramer CK, Zinman B. Cardiovascular disease and the use of insulin. Diabetes Technol Ther. 2013; 15(10): 789-791, doi: 10.1089/ /dia.2013.0223, indexed in Pubmed: 23991630.

44. Monnier L, Hanefeld M, Schnell O, et al. Insulin and atherosclerosis: how are they related? Diabetes Metab. 2013; 39(2): 111-117, doi: 10.1016/j.diabet.2013.02.001, indexed in Pubmed: 23507269.

45. Gamble JM, Simpson SH, Eurich DT, et al. Insulin use and increased risk of mortality in type 2 diabetes: a cohort study. Diabetes Obes Metab. 2010; 12(1): 47-53, doi: 10.1111/j.14631326.2009.01125.x, indexed in Pubmed: 19788429.

46. Currie CJ, Peters JR, Tynan A, et al. Survival as a function of $\mathrm{HbA}(1 \mathrm{c})$ in people with type 2 diabetes: a retrospective cohort study. Lancet. 2010; 375(9713): 481-489, doi: 10.1016/S01406736(09)61969-3, indexed in Pubmed: 20110121.

47. Colayco DC, Niu F, McCombs JS, et al. A1C and cardiovascular outcomes in type 2 diabetes: a nested case-control study. Diabetes Care. $2011 ;$ 34(1): 77-83, doi: 10.2337/dc10-1318, indexed in Pubmed: 20937686.
48. Margolis DJ, Hoffstad O, Strom BL. Association between serious ischemic cardiac outcomes and medications used to treat diabetes. Pharmacoepidemiol Drug Saf. 2008; 17(8): 753-759, doi: 10.1002/pds.1630, indexed in Pubmed: 18613215.

49. Smooke S, Horwich TB, Fonarow GC. Insulin-treated diabetes is associated with a marked increase in mortality in patients with advanced heart failure. Am Heart J. 2005; 149(1): 168-174, doi: 10.1016/j.ahj.2004.07.005, indexed in Pubmed: 15660049.

50. Bruno G, Merletti F, Boffetta P, et al. Impact of glycaemic control, hypertension and insulin treatment on general and cause-specific mortality: an Italian population-based cohort of type II (non-insulin-dependent) diabetes mellitus. Diabetologia. 1999; 42(3): 297-301, doi: 10.1007/s001250051154, indexed in Pubmed: 10096781.

51. Kleinman JC, Donahue RP, Harris MI, et al. Mortality among diabetics in a national sample. Am J Epidemiol. 1988; 128(2): 389-401, doi: 10.1093/oxfordjournals.aje.a114979, indexed in Pubmed: 3394705.

52. Liu QZ, Knowler WC, Nelson RG, et al. Insulin treatment, endogenous insulin concentration, and ECG abnormalities in diabetic Pima Indians. Cross-sectional and prospective analyses. Diabetes. 1992; 41(9): 1141-1150, doi: 10.2337/diab.41.9.1141, indexed in Pubmed: 1499865.

53. Mogensen UM, Andersson C, Fosbøl EL, et al. Cardiovascular safety of combination therapies with incretin-based drugs and metformin compared with a combination of metformin and sulphonylurea in type 2 diabetes mellitus - a retrospective nationwide study. Diabetes Obes Metab. 2014; 16(10): 1001-1008, doi: 10.1111/dom.12314, indexed in Pubmed: 24827939.

54. Roumie CL, Greevy RA, Grijalva CG, et al. Association between intensification of metformin treatment with insulin vs sulfonylureas and cardiovascular events and all-cause mortality among patients with diabetes. JAMA. 2014; 311(22): 2288-2296, doi: 10.1001/ /jama.2014.4312, indexed in Pubmed: 24915260.

55. Rensing KL, Reuwer AQ, Arsenault BJ, et al. Reducing cardiovascular disease risk in patients with type 2 diabetes and concomitant macrovascular disease: can insulin be too much of a good thing? Diabetes Obes Metab. 2011; 13(12): 1073-1087, doi: 10.1111/j.1463-1326.2011.01468.x, indexed in Pubmed: 21736687.

56. Ghosal S. Cardio Vascular Outcomes Trials (CVOTs) with AntiHyperglycemic Agents: Demystifying Statistical Complexities. Journal of Diabetes, Metabolic Disorders \& Control. 2017; 4(4): 104-108, doi: 10.15406/jdmdc.2017.04.00116.

57. Geiger MJ, Mehta C, Turner JR, et al. Clinical Development Approaches and Statistical Methodologies to Prospectively Assess the Cardiovascular Risk of New Antidiabetic Therapies for Type 2 Diabetes. Ther Innov Regul Sci. 2015; 49(1): 50-64, doi: 10.1177/2168479014549860, indexed in Pubmed: 30222452.

58. Spruance SL, Reid JE, Grace M, et al. Hazard ratio in clinical trials. Antimicrob Agents Chemother. 2004; 48(8): 2787-2792, doi: 10.1128/AAC.48.8.2787-2792.2004, indexed in Pubmed: 15273082.

59. Piaggio G, Elbourne DR, Pocock SJ, et al. CONSORT Group. Reporting of noninferiority and equivalence randomized trials: extension of the CONSORT 2010 statement. JAMA. 2012; 308(24): 2594-2604, doi: 10.1001/jama.2012.87802, indexed in Pubmed: 23268518.

60. Rich JT, Neely JG, Paniello RC, et al. A practical guide to understanding Kaplan-Meier curves. Otolaryngol Head Neck Surg. 2010; 143(3): 331-336, doi: 10.1016/j.otohns.2010.05.007, indexed in Pubmed: 20723767.

61. Barraclough H, Simms L, Govindan R. Biostatistics primer: what a clinician ought to know: hazard ratios. J Thorac Oncol. 2011; 6(6): 978-982, doi: 10.1097/JTO.0b013e31821b10ab, indexed in Pubmed: 21623277.

62. Stout RW. Insulin and atheroma. 20-Yr perspective. Diabetes Care. 1990; 13(6): 631-654, doi: http://care.diabetesjournals.org/ /content/13/6/631, indexed in Pubmed: 2192848. 
63. Schneider DJ, Nordt TK, Sobel BE. Attenuated fibrinolysis and accelerated atherogenesis in type II diabetic patients. Diabetes. 1993; 42(1): 1-7, doi: 10.2337/diabetes.42.1.1, indexed in Pubmed: 8420806.

64. Diabetes Control and Complications Trial, Epidemiology of Diabetes Interventions and Complications Research Group. Intensive diabetes therapy and carotid intima-media thickness in type 1 diabetes mellitus. N Engl J Med. 2003; 348(23): 2294-2303, doi: 10.1056/NEJMoa022314, indexed in Pubmed: 12788993.

65. Diabetes Control and Complications Trial, Epidemiology of Diabetes Interventions and Complications Research Group. Intensive Diabetes Treatment and Cardiovascular Disease in Patients with Type 1 Diabetes. N Engl J Med. 2005; 353(25): 2643-2653, doi: 10.1056/nejmoa052187.

66. Feinglos MN, Bethel MA. Therapy of type 2 diabetes, cardiovascular death, and the UGDP. Am Heart J. 1999; 138(5 Pt 1): S346-S352, doi: 10.1016/s0167-0115(99)90004-2, indexed in Pubmed: 10539796.

67. Holman RR, Paul SK, Bethel MA, et al. 10-year follow-up of intensive glucose control in type 2 diabetes. N Engl J Med. 2008; 359(15): 1577-1589, doi: 10.1056/NEJMoa0806470, indexed in Pubmed: 18784090 .

68. Gerstein HC, Bosch J, Dagenais GR, et al. ORIGIN Trial Investigators. Basal insulin and cardiovascular and other outcomes in dysglycemia. N Engl J Med. 2012; 367(4): 319-328, doi: 10.1056/ /NEJMoa1203858, indexed in Pubmed: 22686416.

69. Kalra S. Auxiliendo, Primum Non Nocere: A Preliminary View of the DEVOTE Trial Comparing Cardiovascular Safety of Insulin Degludec Versus Insulin Glargine in Type 2 Diabetes. Diabetes Ther. 2017; 8(2): 213-217, doi: 10.1007/s13300-017-0235-x, indexed in Pubmed: 28197833.

70. Buse JB. Glycemic Targets in Diabetes Care: Emerging Clarity after Accord. Trans Am Clin Climatol Assoc. 2015; 126: 62-76, indexed in Pubmed: 26330660.

71. Schnell O, Standl E, Catrinoiu D, et al. Report from the 3rd Cardiovascular Outcome Trial (CVOT) Summit of the Diabetes \&
Cardiovascular Disease (D\&CVD) EASD Study Group. Cardiovasc. 2018; 17: 30 .

72. Johnson JA, Simpson SH, Eurich DT, et al. Comment on: Evans JM, Ogston SA, Emslie-Smith A, Morris A (2006) Risk of mortality and adverse cardiovascular outcomes in type 2 diabetes: a comparison of patients treated with sulfonylureas and metformin. Diabetologia 49: 930-936, doi: 10.1007/s00125-006-0323-3, indexed in Pubmed: 16788800.

73. Rao AD, Kuhadiya N, Reynolds $K$, et al. Is the combination of sulfonylureas and metformin associated with an increased risk of cardiovascular disease or all-cause mortality?: a metaanalysis of observational studies. Diabetes Care. 2008; 31(8): 1672-1678, doi: 10.2337/dc08-0167, indexed in Pubmed: 18458139.

74. ORIGIN Trial Investigators. Cardiovascular and Other Outcomes Postintervention With Insulin Glargine and Omega-3 Fatty Acids (ORIGINALE). Diabetes Care. 2016; 39(5): 709-716, doi: 10.2337/ /dc15-1676, indexed in Pubmed: 26681720.

75. Lenzen M, Ryden L, Ohrvik J, et al. Euro Heart Survey Investigators. Diabetes known or newly detected, but not impaired glucose regulation, has a negative influence on 1-year outcome in patients with coronary artery disease: a report from the Euro Heart Survey on diabetes and the heart. Eur Heart J. 2006; 27(24): 2969-2974, doi: 10.1093/eurheartj/ehl363, indexed in Pubmed: 17090612.

76. Malmberg K, Rydén L, Wedel H, et al. DIGAMI 2 Investigators. Intense metabolic control by means of insulin in patients with diabetes mellitus and acute myocardial infarction (DIGAMI 2): effects on mortality and morbidity. Eur Heart J. 2005; 26(7): 650-661, doi: 10.1093/eurheartj/ehi199, indexed in Pubmed: 15728645 .

77. Marso SP, McGuire DK, Zinman B, et al.; DEVOTE Study Group Efficacy and Safety of Degludec versus Glargine in Type 2 Diabetes. N Engl J Med. 2017; 377(8): 723-732. doi: 10.1056/ /NEJMoa1615692. Epub 2017 Jun 12. 